\title{
MICROSTRIP LOW PASS FILTER DESIGNS USING DEFECTED GROUND STRUCTURE
}

\author{
Dhara Gadhvi ${ }^{1}$, Urvik Shah ${ }^{2}$ \\ ${ }^{1}$ Assistant Professor, Department of Electronics \& Communication Engineering, Babaria Institue of Technology, \\ Gujarat, India \\ ${ }^{2}$ Assistant Professor, Department of Electronics \& Communication Engineering, Babaria Institue of Technology, \\ Gujarat, India
}

\begin{abstract}
The microwave filters play an important role in most RF/microwave applications. They are designed to remove undesired harmonics to reduce the system noise or to remove spurious mixing products. DGS slot with an interdigital shape are introduced here in two elliptic low pass filter designs. Here a fifth order low pass filter was designed, simulated and fabricated for a cut off frequency of $3 \mathrm{GHz}$. Finally a prototype model were designed based on the simulation results obtained. These prototype filter designs have more than $20 \mathrm{~dB}$ of stop band rejection and a good return loss in the pass band. The fabricated results proved to be better than the simulation results. In the first low pas filter design the central aperture was replaced with the interdigital slot structure which improved the stop band response at the resonant frequency around $7.8 \mathrm{GHz}$. To improve the stop band rejection two interdigital structures were introduced in the bottom layer (Ground).
\end{abstract}

Key Words: Defected ground structure (DGS), low pass filters, microstrip filter, transmission zero.

\section{INTRODUCTION}

In recent years there is increasing demand for broader bandwidth in wireless communication systems and many researches are going on the wideband filters [1-4]. In this work the Defected Ground Structures (DGS) [5-10] presented here is to improve the performance of a traditional microstrip low pass filters. The different applications in passive circuits like low pass filters and band pass filters has given origin to the Defected Ground Structure (DGS). The Defected Ground structure (DGS) have better stop band rejection which are helpful in improving characteristics of certain devices like efficiency of power amplifiers is increased, performance of certain amplifiers and antennas is enhanced, harmonic filtering, also size of microwave circuits is reduced. The resonant frequency of the microstrip line structure is varied or controlled by modifying the shape and size of the slot. For improving the pass band responses of the microstrip filters useful design equations are given. Here two elliptic low pass filter designs were designed and simulated than fabricated on an FR-4 substrate with a relative dielectric constant of 4.4 and thickness of $1.2 \mathrm{~mm}$ [3],[4]. One transmission zero is introduced in the first low pass filter design by replacing the central aperture with interdigital structure which consists of metal fingers. The resonant frequency of the structure can be controlled by varying the distance between these metal fingers but keeping the area occupied by the slot constant. Two transmission zeroes are introduced in the second low pass filter design in the two slots with same finger lengths to improve the stop band response. The two transmission zero design has better response than one transmission zero design for passband and stop band. The resonant frequency of the slot can be varied without changing the slot size by changing the number of metal fingers [13-20]. In the figure 1 the interdigital DGS slot [4] introduced here is shown. In this technical note all dimensions are in $\mathrm{mm}$. Under the microstrip line in the top layer the slot is etched in the bottom layer which is the ground metal layer. The major advantage to this microstrip line is the tighter capacitive coupling provided by the slot in the bottom layer with the interdigital DGS. This replaces the slot capacitances by the interdigital capacitance. The area of DGS can be reduced effectively by using interdigital DGS in the design of miniature devices. By modifying the number of metal fingers keeping the slot size unchanged the change in resonant frequency can be realized. In the one transmission zero design the center slot is replaced by the interdigital DGS where the slot has width of $4.9 \mathrm{~mm}$ and length of 5.65 $\mathrm{mm}$. There are total 6 metal fingers which have a width of $0.4 \mathrm{~mm}$ and length $3.2 \mathrm{~mm}$. By increasing length 1 of the metal fingers the resonant frequency of the slot and capacitance are increased. From the total 3 slots in the bottom layer the dimensions of the center slot is as described above and the other two slots have width $4.9 \mathrm{~mm}$ and length of $3.75 \mathrm{~mm}$. In the two transmission zero design also the dimension of center slot is same as first design but the other two slots are replaced by interdigital DGS where the metal fingers are of width $0.535 \mathrm{~mm}$ and length of $4 \mathrm{~mm}$. By these changes in the low pass filter designs the resonance is brought down to a remarkable level which is shown in fig. 11 and 12 .

All the three fabricated low pass filter designs have the length of $25.6 \mathrm{~mm}$ and breadth of $11.6 \mathrm{~mm}$. 
2. MICROSTRIP LOW-PASS FILTER DESIGN GEOMETRY AND MATERIAL PARAMETERS WITH DGS INTRODUCING SLOTS IN GROUND LAYER

The cut-off frequency of the low-pass filter can be adjusted by setting proper values of the lumped elements of the filter [8-12] can be adjusted as per the requirement. Based on the characteristic impedance $Z_{0}$, effective dielectric constant $\varepsilon_{\text {eff }}$ and the dielectric constant $\varepsilon_{\mathrm{r}}$ which is 4.4 for the FR-4 substrate, the capacitor and inductance values of the filter elements by the stubs of the high/low impedance transmission lines are calculated. The height of substrate which in these designs is $\mathrm{h}=1.2 \mathrm{~mm}$ and the $\varepsilon_{\text {eff }}$ is calculated based on the ratio of the width $\mathrm{w}$ of the transmission line and height $h$.

From the following equation the effective dielectric constant can be found [1-4].

If $\mathrm{W} / \mathrm{h} \geq 1$ :

$\varepsilon_{\text {eff }}=\frac{\varepsilon_{r+1}}{2}+\frac{\varepsilon_{r-1}}{2}\left(1+12 \frac{h}{W}\right)^{-0.5}$.

If $\mathrm{W} / \mathrm{h} \leq 1$ :

$$
\varepsilon_{\text {eff }}=\frac{\varepsilon_{r+1}}{2}+\frac{\varepsilon_{r-1}}{2}\left\{\left[1+12 \frac{h}{W}\right]^{-0.5}+0.04\left[1-\frac{W}{h}\right]^{2}\right\}
$$

The phase velocity $v_{p}$ is calculated from

$$
v_{p}=\frac{c}{\sqrt{\varepsilon_{e f f}}}
$$

Where c represents the velocity of light. The transmission line length $l$ can be calculated from the equations as follows

$$
l=\frac{L v_{p}}{Z_{O}} \text {. }
$$

$$
l=C Z_{o} v_{p}
$$

With the help of commercial simulator the characteristic impedance $\mathrm{Z}_{\mathrm{O}}$ and the width $\mathrm{W}$ are calculated. The filter layout is constructed based on these calculations.

The approximate transmission line calculations are $\mathrm{W}=$ $0.34 \mathrm{~mm}, \mathrm{Z}_{\mathrm{O}}=100 \Omega, \quad l=2.85 \mathrm{~mm}$ and $\mathrm{L}=1.6 \mathrm{nH}$. For $\mathrm{W}$ $=8 \mathrm{~mm} \quad \mathrm{Z}_{\mathrm{O}}=20 \Omega, \quad l=3.48 \mathrm{~mm}$ and $\quad C=1.15 \mathrm{pF}$. For characteristic impedance $\mathrm{Z}_{\mathrm{O}}=50 \Omega, \mathrm{W}=2 \mathrm{~mm}$.
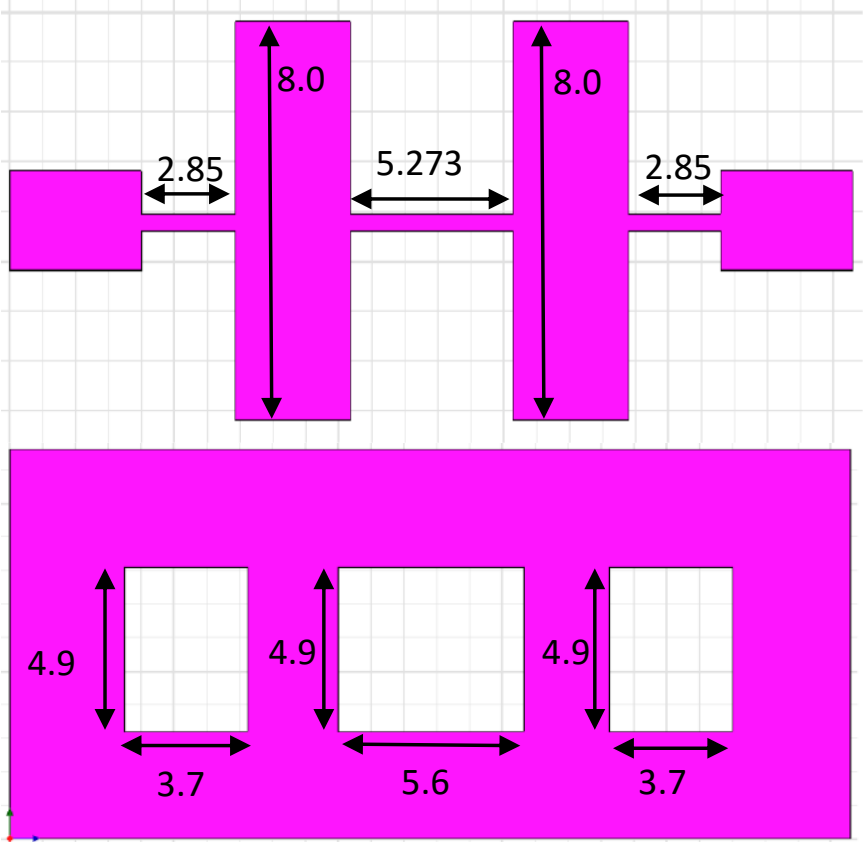

Fig -1: Top (above) and bottom (below) layouts of a fifth order microstrip low-pass filter with slots under the transmission lines. (All dimensions are in $\mathrm{mm}$ )
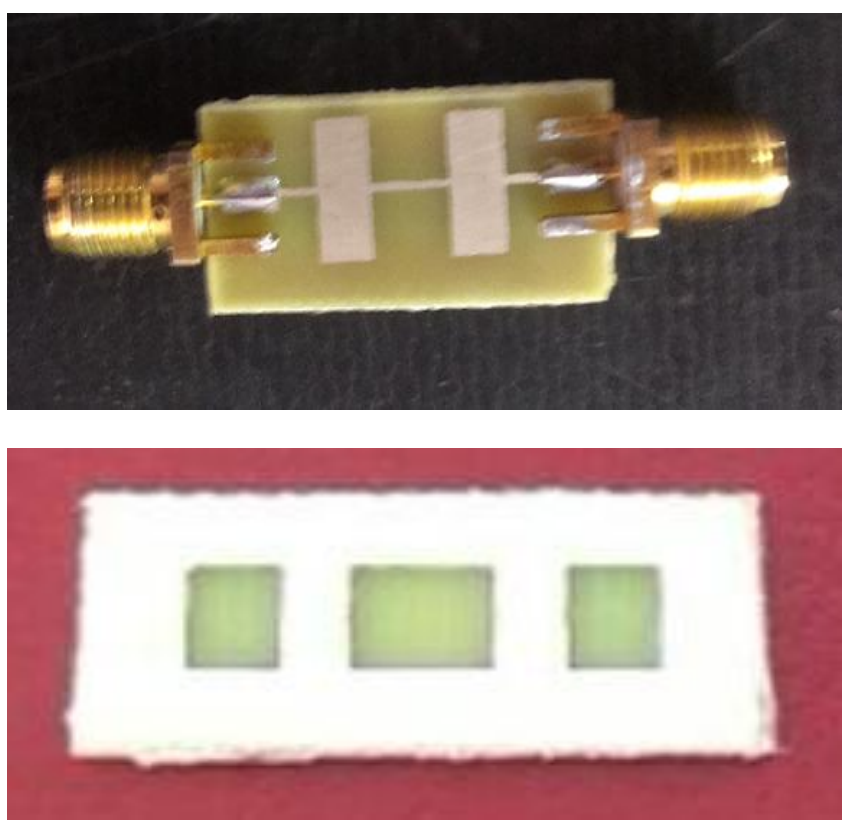

Fig -2: Top (above) and bottom (below) Layers of a fifth order Microstrip low-pass filter (Fabricated).

The first low pass filter design is shown in figure (1) where there are three apertures in the ground layer. The dimension in the figure are in $\mathrm{mm}$. In this design the slots were inserted in ground metallization layer under the low pass filter transmission line which is in the top layer. In the ground layer the two side slots have width of $4.9 \mathrm{~mm}$ and the length of $3.75 \mathrm{~mm}$. The center slot has width of $4.9 \mathrm{~mm}$ and length of $5.65 \mathrm{~mm}$. In Figure 2 the fabricated low pass filter are shown, it shows the top layer of 5th order filter along with the bottom layer with three apertures in the ground layer. The filter designs were tested with the help of SMA 
connectors connected at the input and output of the filters. Here no transmission zeroes were introduced in the design. The transmission zeroes are introduced by replacing the apertures in the ground layer [4]. This leads to the designs introducing transmission zeroes. Fig. 3 shows the simulation results for the insertion and return loss of the low-pass filter without the use of transmission zero design. In the Fig. 3 a resonance is observed around $7.8 \mathrm{GHz}$ which has as insertion loss (S21) of $-14 \mathrm{~dB}$ approx. There is another resonance around $7.9 \mathrm{GHz}$ which has an insertion loss of $41 \mathrm{~dB}$. This design has the pass band insertion loss of $-0.1 \mathrm{~dB}$ and it matches with the simulation results shown in Fig. 3. The minimum return loss in the pass band is $-13 \mathrm{~dB}$. Fig. 4 shows the tested results of the fabricated low pass filter taken on the Scalar Network Analyzer. The results after fabrication have proved to be better than the simulation results. The stop band rejection of the filter are almost same in the simulated and tested results and the resonance at 7.8 $\mathrm{GHz}$ is very low in the tested results compared to the simulation one. It has maximum insertion loss in the pass band of $-0.43 \mathrm{~dB}$. The $2 \mathrm{nd}$ harmonic at $6 \mathrm{GHz}$ has insertion loss of $-18.74 \mathrm{~dB}$ and $3 \mathrm{rd}$ harmonic at $9 \mathrm{GHz}$ has insertion loss of $-22.22 \mathrm{~dB}$.

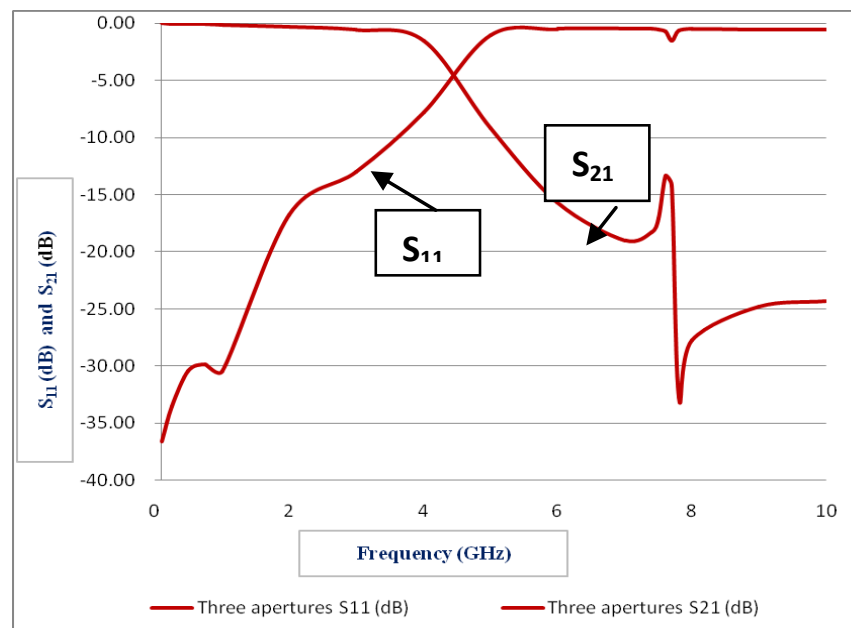

Fig -3: Simulation Result for Insertion loss (S21) and return loss (S11) of a fifth order low-pass filter.

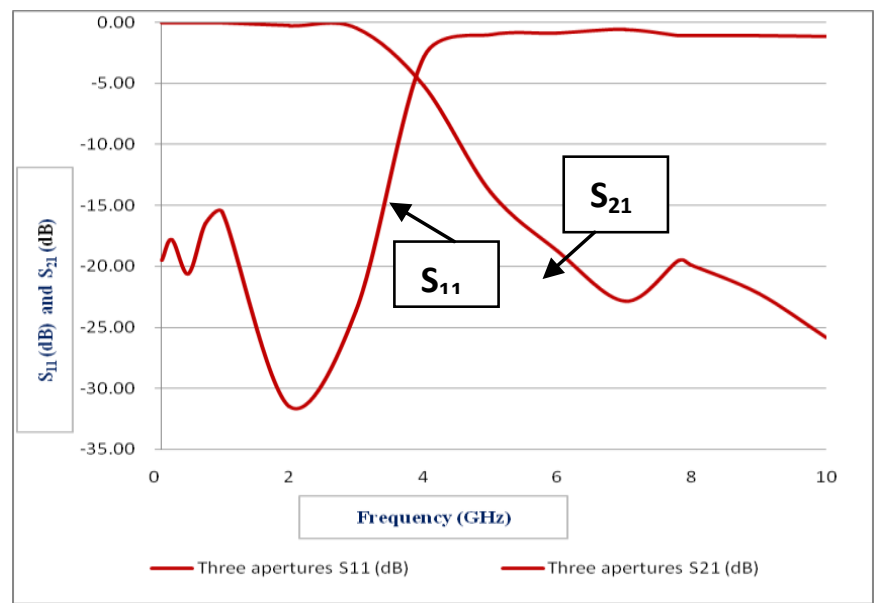

Fig -4: Hardware Testing Results on Scalar Network Analyzer for Insertion loss (S21) and return loss (S11) of a fifth order low-pass filter.

\section{MICROSTRIP LOW-PASS FILTER DESIGN GEOMETRY AND MATERIAL PARAMETERS WITH ONE TRANSMISSION ZERO}

To improve the stop band response a one transmission zero design was introduced in the center slot of ground layer in the form of interdigital slot structure. The passband return loss and insertion loss are not affected but the cut off frequency can be changed by varying the dimensions of the slot in the form of width and length. The metal finger has a width of $0.4 \mathrm{~mm}$ and length of $3.2 \mathrm{~mm}$. The cut off can be shifted back by reducing the inductance of the narrow line [4],[8]. By increasing the width of the strip the inductance can be reduced. The dimensions of the transmission line in top layer are the same as previous designs. The fabricated low pass filter design with one transmission zero is shown in Fig. 6 in which only the bottom layer with interdigital slots in the middle. Top layer is same as shown in Fig. 2. The fabricated low pass filter was tested on Scalar Network Analyzer and its tested results are shown in Fig. 8. It has maximum insertion loss in the pass band of $-0.46 \mathrm{~dB}$. The 2 nd harmonic at $6 \mathrm{GHz}$ has insertion loss of $-21.64 \mathrm{~dB}$ and $3 \mathrm{rd}$ harmonic at $9 \mathrm{GHz}$ has insertion loss of $-21.01 \mathrm{~dB}$.
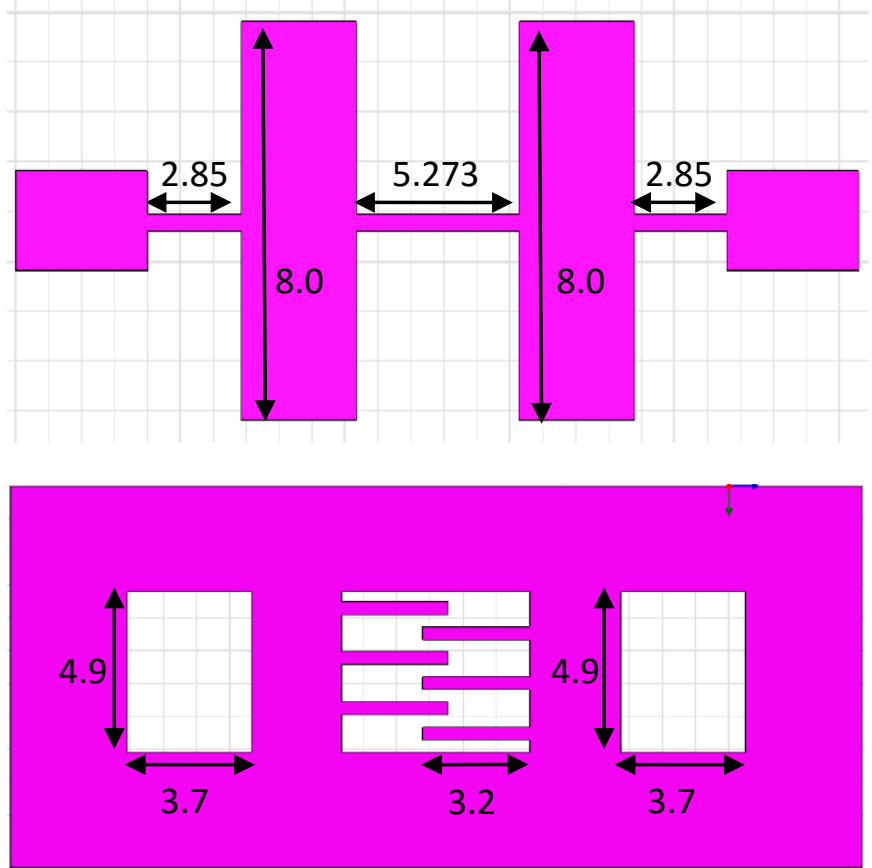

Fig-5: Top (above) and bottom (below) layouts of a fifth order microstrip low-pass filter with one transmission zero. (All dimensions are in $\mathrm{mm}$ ) 


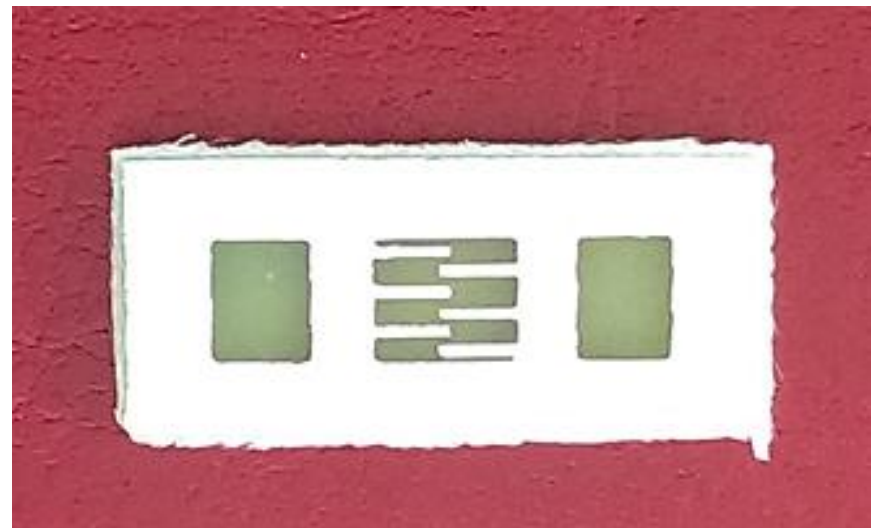

Fig-6: Bottom Layer of a fifth order Microstrip low-pass filter (Fabricated).

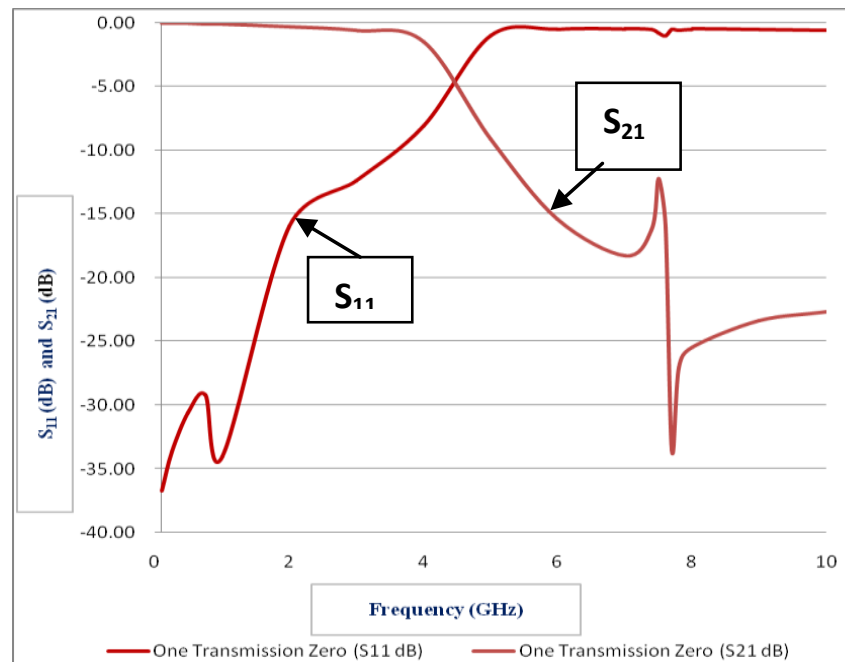

Fig-7: Simulation Result for Insertion loss (S21) and return loss (S11) of a fifth order low-pass filter.

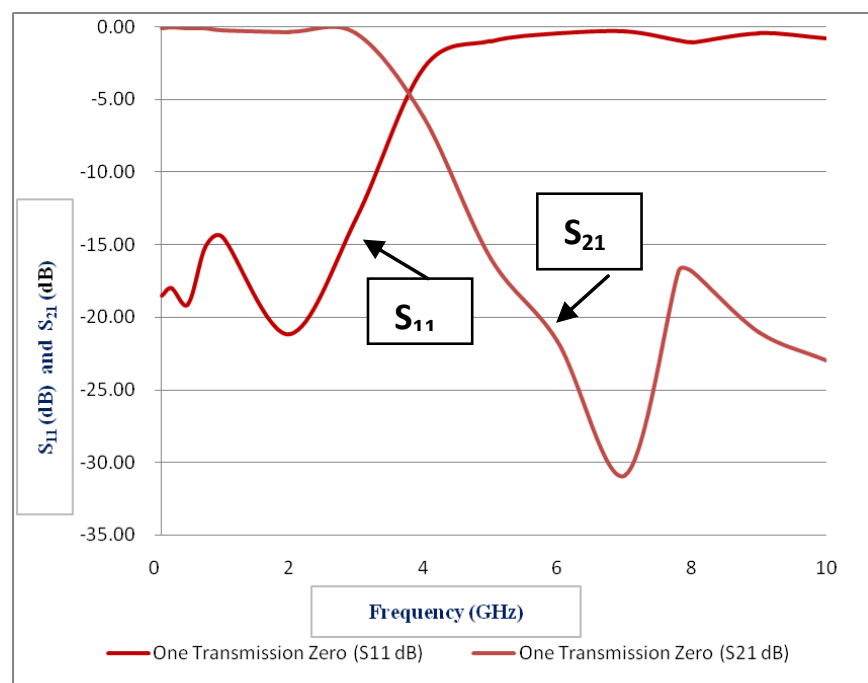

Fig-8: Hardware Testing Results on Scalar Network Analyzer for Insertion loss (S21) and return loss (S11) of a fifth order low-pass filter for One Transmission Zero Design.

\section{MICROSTRIP LOW-PASS FILTER DESIGN GEOMETRY AND MATERIAL PARAMETERS WITH TWO TRANSMISSION ZEROES}

In the Fig. 9 the top and bottom (ground) layer layout of two transmission zeroes is shown. Here in the ground metallization two interdigital slots are introduced as shown in Fig. 9. The two slots with interdigital DGS has a width of $4.9 \mathrm{~mm}$ and length of $3.75 \mathrm{~mm}$. The center aperture has no interdigital DGS and has a width of $4.9 \mathrm{~mm}$ and length of $5.65 \mathrm{~mm}$. In these interdigital structures the metal fingers have a width of $0.535 \mathrm{~mm}$ and length of $4 \mathrm{~mm}$. In the figure 11 the simulation results are shown.

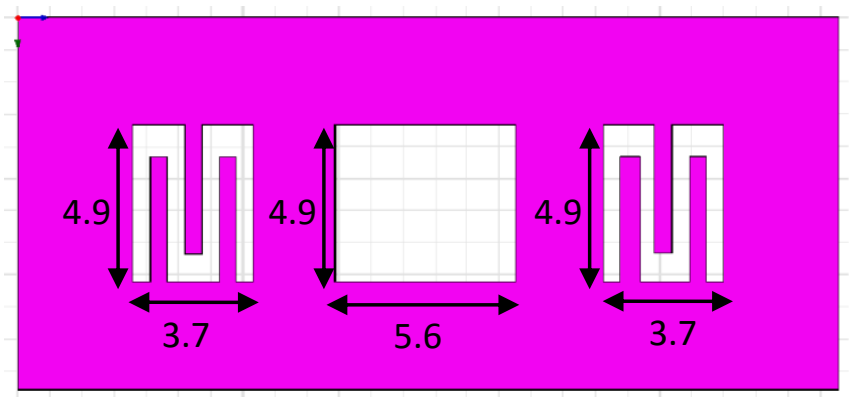

Fig -9: Top (above) and bottom (below) layouts of a fifth order microstrip low-pass filter with two transmission zeroes. (All dimensions are in $\mathrm{mm}$ )

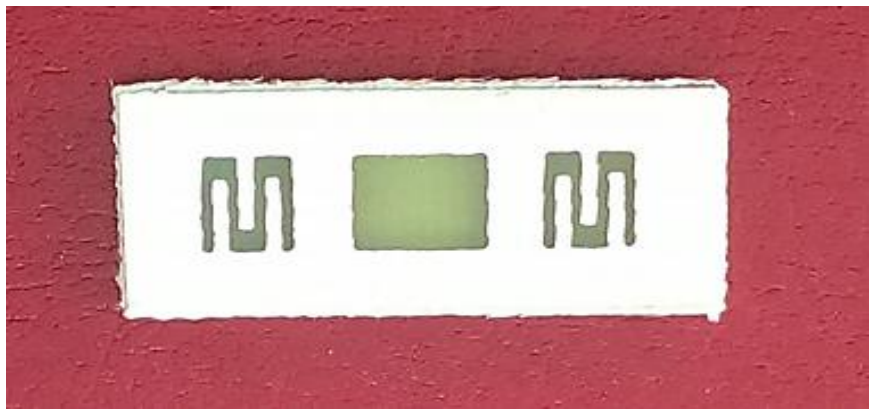

Fig -10: Bottom Layer of a fifth order Microstrip low-pass filter (Fabricated).

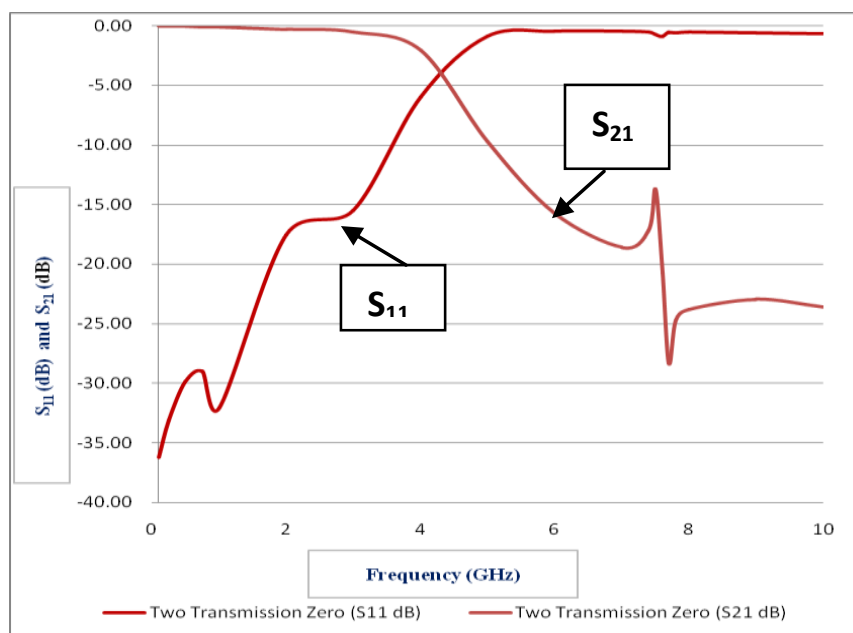

Fig -11: Simulation Result for Insertion loss (S21) and return loss (S11) of a fifth order low-pass filter. 


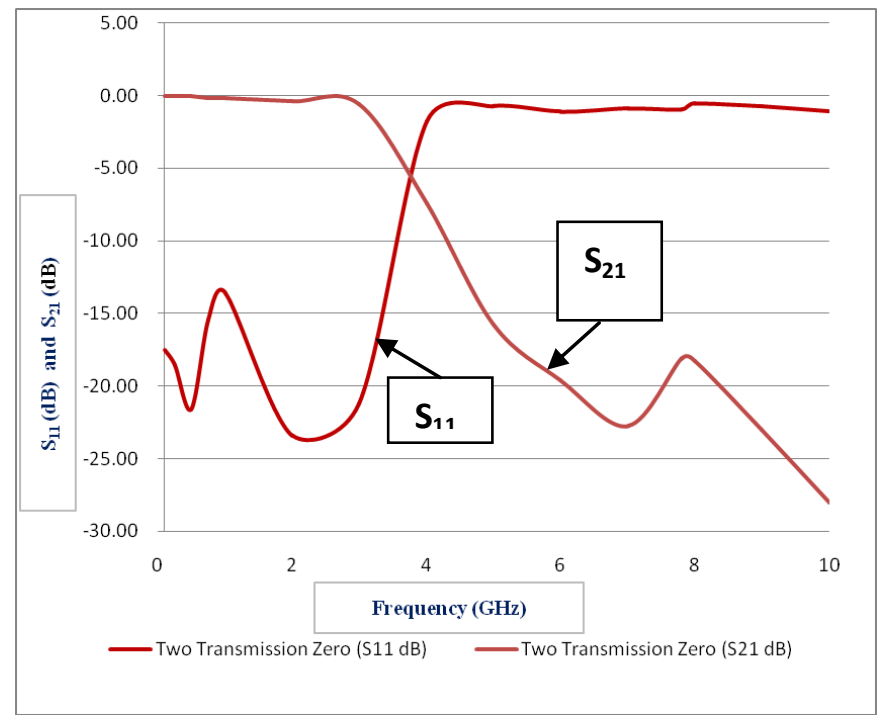

Fig -12: Hardware Testing Results on Scalar Network Analyzer for Insertion loss (S21) and return loss (S11) of a fifth order low-pass filter for Two Transmission Zero Design.

The fabricated low pass filter design with two transmission zero is shown in Fig. 10 in which only the bottom layer with interdigital slots at the right and left side are shown. Top layer is same as shown in Fig. 2. The fabricated low pass filter was tested on Scalar Network Analyzer and its tested results are shown in Fig. 12. It has maximum insertion loss in the pass band of $-0.58 \mathrm{~dB}$. The $2 \mathrm{nd}$ harmonic at $6 \mathrm{GHz}$ has insertion loss of $-19.6 \mathrm{~dB}$ and $3 \mathrm{rd}$ harmonic at $9 \mathrm{GHz}$ has insertion loss of $-23.04 \mathrm{~dB}$. Thus harmonics in the stop band are brought down considerably.

\section{CONCLUSION}

A fifth order low pass filter was designed and simulated first and its prototype models were developed. These filters were designed for the cut off of $3 \mathrm{GHz}$. By properly selecting impedances of the transmission lines bandwidth of the broadband low pass filter can be independently designed. This technical note also introduces interdigital DGS structure in the slots introduced in the ground layer. The main advantage of the proposed structures is to get a wide stop band with a very compact design. You can observe from the results obtained that the fabricated LPF shows better results in the stop band behavior than the simulation results and has stop band rejection of more than $20 \mathrm{~dB}$. Thus a microstrip elliptic low pass filter with a good pass band return loss and better stop band insertion loss is achieved.

\section{ACKNOWLEDGEMENT}

The authors can acknowledge any person/authorities in this section. This is not mandatory.

\section{REFERENCES}

[1]. Ching-Wen Tang and Ming-Guang Chen, "A Microstrip Ultra-Wideband Bandpass Filter with Cascaded Broadband Bandpass and Bandstop Filters," IEEE Transactions On
Microwave Theory and Techniques Vol.55, no.11, pp. 24122418, Nov 2007.

[2]. R A. K. Tiwary, and N. Gupta, "Performance of Microstrip Low-Pass Filter on Electromagnetic Band Gap Ground Plane," IETE Journal of Research, vol.56, Sep-Oct 2010

[3]. Hong-Ming Lee and Ching-Ming Tsai, "Improved Coupled Microstrip Filter Design Using Effective Evenmode and Odd-mode Characteristic Impedances," IEEE Transactions On Microwave Theory and Techniques Vol.53, no.9, pp. 2812-2818 ,Sept 2005.

[4] D.D. Gadhvi, S.K. Patel and Yogeshwar Kosta, "Elliptic Low Pass Filter Design Using DGS Slots for Microstrip Lines," 2013 Nirma University International Conference On Engineering Nuicone-2013, Nov 2013.

[5] A. Balalem, A. R. Ali, J. Machac, Senior Member, IEEE, and A. Omar, Fellow, IEEE ,"Quasi-Elliptic Microstrip Low-Pass Filters Using an Interdigital DGS slot," IEEE Microwave and Wireless Components Letters, pp. 15371309, 2007.

[6] D. K. Mishra, Radio-Frequency and Microwave Communication Circuits: Analysis and Design,, John Wiley and sons Inc., pp. 295-353, 2001

[7] Jia-Sheng Hong, M. J. Lancaster ,Microstrip Filters for RF/Microwave Applications, John Wiley and sons Inc.,pp.29-76, 2001

[8] S. V. Al-Din Makki, A. Ahmadi, S. Majidifar, H. Sariri, and Z. Rahmani, "Sharp Response Microstrip LPF using Folded Stepped Impedance Open Stubs," Radio engineering, vol.22, no. 1, pp. 328-332, Apr. 2013.

[9]. A. Terado-Mendez, H.Jardon-Aguilar, and R. Flores Leal, "Improving Frequency Response of Microstrip Filters using Defected Ground and Defected Microstrip Structures," Progress in Electromagnetic Research C, vol. 13, pp. 77-90, 2010.

[10]. Shao Ying Huang and Yee Hui Lee, "Tapered DualPlane Compact Electromagnetic Bandgap Microstrip Filter Structures," IEEE Transactions On Microwave Theory and Techniques Vol.53, no.9, pp. 2656-2664 ,Sept 2005.

[11]. T. Moyra, S. Kumar Parui, and S. Das, "Design and Development of Low Pass Filter and Harmonics Reduction," International Journal on Electrical Engineering and Informatics, vol. 3, no. 3, pp. 336-349, Oct. 2011.

[12]. L. Wang, H. C. Yang, and Y. Li, "Design Of Compact Microstrip Low- Pass Filter with Ultra-Wide Stop Band Using SIRS," Progress in Electromagnetic Research, vol. 18, pp. 179-186, 2010.

[13]. X. Q. Chen, R. Li, S. J. Shi, Q. Wang, L. Xu, and X. W. Shi, "A Novel Low Pass Filter Using Elliptic Shape Defected Ground Structure," Progress in Electromagnetic Research B, vol. 9, pp. 117-126, 2008.

[14]. A. Ortega, L. R. A. X. De Menezes, A. J. Martins Soares, and H. Abdalla Jr., "Design Of Low-Pass Microstrip Filters Based On Defected Ground Structures," IEEE MTTS International Microwave and Optoelectronics Conference (IMOC), pp. 69-74, Oct. 2011.

[15]. J. M. Patel, S. K. Patel, and F. N. Thakkar, "Defected Ground Structure Multiband Microstrip Patch Antenna Using Complementary Split Ring Resonator," International 
Journal Of Emerging Trends in Electrical and Electronics, vol. 3, May 2013.

[16]. S. K Patel and Yogeshwar Kosta, “ Triband Microstrip-Based Radiating Structure Design Using Split Ring Resonator and Complementary Split Ring Resonator," Microwave and Optical Technology Letters, vol. 55, no. 9, pp. 2219-2222-349, Sept. 2013.

[17]. M. Naser-Moghadasi, R. A. Sadeghzadeh, S. Y. Fard, and B. S. Virdee, "Microstrip Low-Pass Filters by Using DGS with Folded T-Shaped Arms," International Scientific Publications and Consulting Services, vol.2012, 2012.

[18]. S. Prabhu, J.S. Mandeep and S. Jovanovic, "Microstrip Bandpass Filter At S Band Using Capacitive Coupled Resonator," Progress in Electromagnetic Research B, pp. 223-228, 2007.

[19]. J. Chen, Z.-B. Weng, Y.-C. Jiao and F.-S. Zhang, "Low Pass Filter Design of Hilbert Curve Ring Defected Ground Structure," Progress in Electromagnetic Research B, pp. 269-280, 2007.

[20]. J. Zhang, B. Cui, S. Lin, and X.-W. Sun, "SharpRejection Low-Pass filter With Controllable Transmission Zero Using Complementary Split Ring Resonators (CSRRS)," Progress in Electromagnetic Research B, pp. 219-226, 2007.

\section{BIOGRAPHIES}

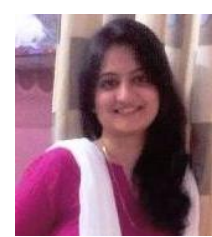

Dhara Gadhvi received B.E. degree in 2006 from SVIT, Gujarat and M. Tech degree in 2014 from CSPIT, CHARUSAT university, Gujarat. Worked as an Electronics Engineer from 2006 to 2011. Currently working as an Assistant Professor in Babaria Institute Of

Technology, Gujarat.

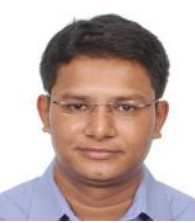

Urvik Shah received B.E. degree in 2009 from BVM, Gujarat and M. Tech degree in 2013 from CSPIT, CHARUSAT university, Gujarat. Currently working as an Assistant Professor in Babaria Institute Of

Technology, Gujarat. 